\title{
Direito à educação: ações afirmativas como política pública para o ingresso no ensino superior
}

Right to education: affirmative actions as a public policy of access to higher education

Fernando Cesar Mendes Barbosa Universidade Estadual do Norte do Paraná, UENP, Brasil Universidade Federal da Integração Latino-Americana, UNILA, Brasil.

FABIANO Simon BRUNETTO Universidade Federal da Integração Latino-Americana, UNILA, Brasil.

Rosilene Alves da Silva Vitorini Universidade Federal da Integração Latino-Americana, UNILA, Brasil

Resumo $\mathrm{O}$ texto discute a maneira pela qual o direito à educação tem sido efetivado por meio de ações afirmativas, consideradas políticas públicas de acesso à educação. Reconhece que a implementação de políticas públicas de acesso ao ensino constituem verdadeiro e legítimo instrumento de diminuição e correção de desigualdades históricas que determinaram e, ainda hoje, permeiam o acesso e a permanência no Ensino Superior Brasileiro. Conclui que, apesar de essas ações afirmativas serem recentes no Brasil, elas têm contribuído para diminuir os grandes espaços que existem entre os mais favorecidos e os mais fragilizados socioeconomicamente.

Palavras-chave: Acesso. EducaÇão Superior. Desigualdades SocioECONÔMICAS. 
Abstract The paper discusses how the right to education has been effectived through affirmative actions, considered public policies of access to higher education. It recognizes that the implementation of these public policies constitute a legitimate instrument for reducing and correcting historical inequalities that have determined and the access and permanence in Brazilian higher education. It concludes that, although these affirmative actions are recent in Brazil, they have contributed to reduce the large spaces that exist between the ones incredibly fragile and the more favored ones socioeconomically.

Key-words: Admission. Higher Education. Socioeconomic inequalities.

\section{INTRODUÇão}

As reflexões sobre as políticas de ações afirmativas têm sido intensificadas nos últimos tempos, principalmente em razão de importantes mudanças propostas no contexto educacional brasileiro (FONSECA, 2009).

Nesse cenário, as ações afirmativas compreendem as iniciativas que objetivam a reparação de injustiças constituídas historicamente, em desfavor de determinados grupos sociais. Assim, o alcance e a efetividade do direito à educação constituem-se finalidades das políticas de ações afirmativas, compreendidas como processo primordial, inclusive, na perspectiva de mobilidade social (PAIXÃO, 2010; SANTOS, 2005).

Atualmente, a reivindicação pela igualdade de direitos ao acesso da população economicamente menos favorecida e de determinados grupos étnico-raciais, ao ensino superior, torna necessárias as reflexões relacionadas à implementação das ações afirmativas, como mecanismos de garantia ao direito fundamental à educação (SILVA, 2016).

$O$ presente trabalho constitui uma abordagem a respeito da implementação de políticas de ações afirmativas de acesso ao ensino superior. Para isso, estabelece um paralelo entre as relações estabelecidas pelo ordenamento jurídico, pelos processos de reivindicações e lutas sociais, que têm lugar em diversos contextos socioeducacionais e pela construção e consolidação das ações afirmativas de acesso às universidades públicas brasileiras. 
Por conseguinte, inicialmente, analisam-se os aspectos legais e jurídicos fundamentais para a articulação e efetivação dos direitos previstos, a partir das ações afirmativas. Em seguida, discute-se o retrato histórico brasileiro, relacionado à segregação e às influências na realidade social, especificamente na busca pela igualdade de acesso à educação, como forma de inclusão social.

Posteriormente, coloca-se em evidência a trajetória de lutas dos movimentos sociais, pela igualdade de direitos e implantação das ações afirmativas, além de aspectos sociais, que estão diretamente relacionados ao sistema educacional. Finalmente, analisam-se as diferentes concepções e formas de implementação das ações afirmativas nas universidades brasileiras, as recentes alterações na legislação e alguns dados relacionados à reconstrução da dinâmica educacional no ensino superior.

\section{AÇões afirmativas COMO POlítica Pública de CONCRETIZAÇÃO DE DIREITOS}

Que o direito não se basta em si mesmo não restam dúvidas. Como um organismo sistêmico, à medida que institucionaliza regras, elege padrões e sanciona condutas, desencadeia uma série de mecanismos para a sua concretização. Ocorre que a norma por si só não se basta. Em outras palavras, direito sem finalidade, primordialmente a social, é letra morta.

Classicamente, os direitos fundamentais têm sido estudados ou compreendidos em gerações dos direitos, ou, mais tecnicamente adequado, dimensões, que evidenciam academicamente as fases de institucionalização do direito (SARLET, 2004, p. 55; BONAVIDES, 2002, p. 515), dessa maneira, tem-se que: na $1^{\text {a }}$ dimensão são reconhecidos os direitos atrelados à liberdade, direitos civis e políticos, de caráter negativo, isto é, implicam uma abstenção estatal em não os agredir; na $2^{\mathrm{a}}$ dimensão são positivados direitos relativos à igualdade, considerados positivos, pois implicam uma prestação estatal em prol de sua realização; já na $3^{\text {a }}$ dimensão, constituem-se os direitos relacionados à fraternidade, considerados direitos de toda a coletividade. Em relação a esse tema, Barbosa e Merheb (2017, p. 253) apontam que: 
...seria possível uma tentativa de compreensão dos direitos fundamentais a partir de dimensões, de maneira que poderiam ser analisados os direitos de primeira dimensão, notadamente aquele grupo de direitos marcados pela liberdade e igualdade, os direitos de segunda dimensão, cujas marcas características remontam aos direitos sociais, principalmente a partir da Constituição Mexicana de 1917 e da Constituição Alemã de Weimar, de 1919, reconhecidas como marcos originários dessa categoria de direitos, e assim poderíamos fazê-lo com os direitos de terceira e quarta dimensões, respeitadas as devidas divergências teóricas e doutrinárias sobre a matéria.

Porém, no contexto normativo nacional atual, enfrenta-se um novo paradigma: vencida a fase de institucionalização, isto é, reconhecimento e positivação dessas garantias, passa-se ao patamar da discussão sobre a concretização. Pois não basta erigir ao nível constitucional inúmeros direitos, formando uma carta de intenções sem políticas concretas de efetivação. É o que afirma João Paulo de Faria Santos:

Apesar de vigorar em nossa Carta Magna uma série de direitos formalmente extensivos a todos os brasileiros, na prática nos acostumamos a conviver com uma perversa sociedade que destina aos mais frágeis, socialmente, o lugar de não-cidadão [...] (2005, p. 15).

É nesse contexto que se inserem as ações afirmativas, em um patamar de direitos positivados, porém, não efetivados, exsurge a necessidade de políticas estatais aptas à promoção da igualdade. E mais do que isso, as ações afirmativas não se prendem apenas à efetivação da igualdade, reconhecem desigualdades históricas e buscam corrigi-las, proporcionando a valorização de uma cultura, da educação, enfim, da inclusão.

É salutar a relação existente entre os direitos de segunda dimensão, tidos como prestações positivas do Estado, de caráter relevantemente social, e as ações afirmativas. A relação existente é direta, mas não se 
confunde, ao passo que as ações afirmativas têm o condão precípuo de efetivar os direitos sociais, eminentemente à educação, foco deste artigo, isto é, consiste em políticas públicas, sejam elas legislativas ou não, de concretização de direitos.

A necessidade de se promover determinados direitos a determinados grupos de pessoas deriva de fatores históricos de segregação social, no qual se evidencia que a norma não se basta para a promoção da inclusão, diante de sua previsão genérica ou da ausência de mecanismos que de fato promovam o direito positivado. Nesse sentido, Dagoberto José Fonseca destaca que:

As ações afirmativas são políticas públicas destinadas a atender grupos sociais que encontrem-se em condições de desvantagem ou vulnerabilidade social em decorrência de fatores históricos, culturais e econômicos (2009, p. 11).

O escopo das ações afirmativas é diversificado, em primeiro momento primam pela inclusão social em iguais condições dessas minorias ou grupos sociais historicamente segregados, num segundo momento, o objetivo é a participação ativa e política na vida do Estado, promovendo verdadeiro reconhecimento da diversidade cultural na construção de um Estado Democrático de Direito, patamar que só é atingido pela mudança da estrutura social, na forma de pensar a construção de uma sociedade plural e igualitária, o que é possível via educação. Em outros termos, não basta garantir a inclusão sem que se possibilite a integração política, social e cultural.

\section{IGUALDADE E EDUCAÇÃo: O BINÔMIO JURÍDICO DA INCLUSÃo SOCIAL}

O retrato histórico da colonização do Brasil remonta à imagem da escravidão dos índios e negros, com a formação de uma sociedade desigual em sua base, cujos privilégios dos senhores desbravadores das ter- 
ras de Vera Cruz têm como base o sangue e o suor da opressão. O Brasil foi um dos últimos países a abolir a escravidão, "somos herdeiros de uma escravidão nefasta e quase interminável" (SANTOS, 2005, p. 17).

Com o fim da escravidão, motivada mais por interesses econômicos do que sociais, relegou-se ao liberto negro a clausura das favelas, da segregação social, da desigualdade. É necessário remontar esse contexto histórico, pois hoje repercute seus reflexos intensamente na realidade social brasileira, portanto, no âmbito da educação, e por ser esse o extrato material das ações afirmativas, que, como já dito, primam pela inclusão e, ao menos, compensação material dessa história nefasta.

Passados séculos de lutas sociais por reconhecimento e inclusão, a discussão ainda é incipiente, muito embora haja conquistas alçadas. Essas discussões têm como pano de fundo o direito e o papel que damos para ele na transformação social, isso implica "ressignificar o papel da Constituição na identidade das sociedades contemporâneas e nas lutas por inclusão" (SANTOS, 2005, p. 12).

Se por um lado temos a Carta Magna afirmando que "todos são iguais perante a lei, sem distinção de qualquer natureza", artigo $5^{\circ}$., caput (BRASIL, 1988), por outro lado temos uma realidade na qual os ditames estampados na Constituição não encontram ressonância, diante da discrepância existente entre brancos e negros e a realidade universitária tem demonstrado isso claramente.

As ações afirmativas, como políticas públicas de inclusão, não se bastam na igualdade descrita no caput do artigo $5^{\circ}$. da Constituição Federal (BRASIL, 1988), pois ali está consolidada a igualdade perante a lei, ou igualdade formal, o Estado - representado por suas leis - não distingue brancos e negros, ricos e pobres, fortes e fracos, trata todos de maneira igual, colocando-os todos no mesmo nível, porém, isso culmina em mais desigualdade, pois duas pessoas em diferentes condições sociais, políticas e econômicas obviamente não terão as mesmas oportunidades e chances.

Se o foco das ações afirmativas é a inclusão, a igualdade a ser estabelecida é a material, no brocado jurídico "tratar igualmente os iguais e desigualmente os desiguais, na medida de suas desigualdades". 
José Afonso da Silva (2012, p. 212) afirma que:

A previsão, ainda que pragmática, de que a República Federativa do Brasil tem como um de seus objetivos fundamentais reduzir as desigualdades sociais e regionais (art. $3^{\circ}$., III), veemente repulsa a qualquer forma de discriminação (art. $3^{\circ}$., IV), a universalidade da seguridade social, a garantia do direito à saúde, à educação baseada em princípios democráticos e de igualdade de condições para o acesso e permanência na escola, enfim a preocupação com a justiça social como objetivo das ordens econômica e social (arts. 170, 193, 196 e 205) constituem reais promessas de busca da igualdade material.

A partir disso é possível afirmar que as ações afirmativas constituem o substrato material do princípio da igualdade, ou seja, um instrumento de concretização da igualdade em sua faceta material, promovendo a inclusão sob todas as suas formas, a justiça social e o reconhecimento da pluralidade, que é base de um Estado Democrático de Direito. Mas, como promover essa inclusão? Por quais instrumentos?

A medida primeira para promover a igualdade de condições é o amplo e irrestrito acesso à educação, garantida na Constituição Federal como (BRASIL, 1988):

[...] direito de todos e dever do Estado e da família, será promovida e incentivada com a colaboração da sociedade, visando ao pleno desenvolvimento da pessoa, seu preparo para o exercício da cidadania e sua qualificação para o trabalho (art. 205).

A igualdade no acesso à educação proporciona a promoção da inclusão e a consolidação, em longo prazo, da integração do grupo objeto da ação afirmativa na vida política do Estado. Por tal motivo, as ações afirmativas são consideradas medidas temporárias.

Não há inclusão sem acesso à educação. A estrutura do ensino básico brasileiro não proporciona aos menos favorecidos igualdade de 
condições no acesso ao ensino superior, há pouco tempo composto quase que por exclusividade pela elite de classe brasileira, resquício ainda premente em alguns cursos de graduação como medicina e engenharia. $\mathrm{O}$ relegado à sua própria sorte, escravo do engenho do passado, hoje se tornou o segregado da educação, por universidades que se enfeixam em feudos modernos para perpetrar os estamentos.

Felizmente, as políticas de inclusão têm mudado esse cenário paulatinamente, pois “A sociedade brasileira já iniciou um processo sem retorno de discussão de como incluir no sistema educacional os grupos étnicos que historicamente foram alijados de direitos básicos" (SANTOS, 2005, p. 15). Certo é que, sem ações afirmativas, a inclusão nunca passará de um desejo utópico, de ilusão ou de esperança, ou da mais pura e sádica manipulação, como já foram outros marcos legislativos que se bastaram ao papel.

\section{LuTAS SOCIAIS E AÇÕES AFIRMATIVAS}

O processo de afirmação e contradição vincula-se a uma essência questionadora, impulsionando a uma superação da visão imediatista, reformulando a percepção voltada ao cotidiano, numa amplitude de aspectos políticos, sociais, e históricos.

As lutas de classes, representadas pelos fatores sociais, econômicos e ideológicos, fundamentam-se na busca por respostas e direitos e o questionamento sobre as condições no contexto social. A História demonstra eventos de posturas autoritárias e arbitrárias, tendo como consequências conflitos, muitas vezes violentos.

O processo de articulação de implementação de ações afirmativas no âmbito nacional perpassa um contexto de lutas, questionamentos e reflexões, protagonizados pelos movimentos sociais. Historicamente no Brasil, os referidos movimentos expressam resistências no contexto escravocrata. Posteriormente ao processo abolicionista e à transformação da situação política do país, com a implantação da República, os antigos trabalhadores rurais concentram-se nas periferias das grandes cidades. As lutas se voltam para as condições de sobrevivência e pelos 
direitos fundamentais. As resistências se consolidam em aspectos religiosos, artísticos e políticos. Apesar das mudanças ocorridas na educação, com o Movimento dos Pioneiros, a proclamação da Constituição de 1934 e 1937, a criação do Ministério da Educação na era Vargas, o processo educacional ainda reflete uma proposta de formação desigual, constituindo uma escola voltada à formação de mão de obra que atenderia aos interesses de expansão industrial do país, e outra voltada à formação da elite dirigente. Apesar da obrigatoriedade e da gratuidade, colocadas nos documentos legais, o acesso aos espaços escolares ainda continua restrito.

Entre as décadas de 1940 e 1950, o enfoque se volta aos movimentos de educação popular, como forma de resistência e superação de uma concepção de educação com ideais opressores. Para Paulo Freire: "Na verdade, o que pretendem os opressores é transformar a mentalidade dos oprimidos e não a situação que os oprimem, e isto para que, melhor adaptando-os a esta situação, melhor os dominem" (1987, p. 60).

Nesse sentido, a educação como instrumento político e ideológico favorece a manutenção de hierarquias sociais, fundamentadas nas desigualdades e discriminações historicamente constituídas. Presume-se que em um processo educativo, de perspectiva inovadora, confere-se à realidade uma condição possível de transformação, por meio da reflexão crítica.

Verifica-se que no período entre os anos marcados pela ditadura militar, as lutas populares se intensificam, e as medidas de repressão militar, ora explícitas e violentas, ora subjetivas, também foram evidentes. No âmbito educacional, as reformulações no ensino propostas pela Lei de Diretrizes e Bases da Educação Nacional, Lei no ${ }^{\circ}$. 5.692/71, tinham como propósito de caráter governamental o envolvimento dos jovens, numa formação "patriótica", evitando vínculos político-partidários. Um exemplo é a obrigatoriedade da disciplina "Educação Moral e Cívica". A dualidade do ensino também permanecia, com os programas de educação profissionalizante e de metodologias de enfoque tecnicistas.

No período de redemocratização e promulgação da Constituição Federal de 1988, a situação econômica e política brasileira tem reflexo 
no contexto educacional, impulsionando os debates para a ampliação de acesso e reformulação das práticas pedagógicas, na Educação Básica e no Ensino Superior. Os movimentos sociais negros e indígenas são partes que compõem esse processo, favorecendo espaços para o diálogo. A articulação para a implementação das políticas de ações afirmativas no âmbito nacional resulta em algumas conquistas por esses movimentos, como o reconhecimento de direitos na Carta Magna, a criação da Fundação Cultural Palmares e o surgimento de novos movimentos sociais, o debate do sistema de cotas na universidade, a aprovação das Leis $n^{\circ}$. 10.639/2003 e 11.645/2008, pelas quais o estudo da história e cultura afro-brasileira e indígena torna-se obrigatório nas escolas de Educação Básica, além da Lei no . 12.711/2012, que contempla a reserva de cotas nos cursos de Ensino Superior em instituições federais.

O debate, atualmente, perpassa o acesso, pois ainda há cursos universitários destinados à formação de profissionais liberais, cujos profissionais exercerão funções de liderança que, em sua maioria, são constituídos por estudantes de situação econômica favorecida. Os desafios e as reflexões no contexto universitário também se voltam para o processo de permanência dos estudantes que ingressam pelo sistema de cotas, tendo em vista que as políticas de ações afirmativas devem orientar medidas concretas, produtoras de efeitos práticos coletivos, fundamentadas na igualdade de oportunidades, condições de reconhecimento e de mobilidade social.

\section{DemocratizaÇão do aCESSO À edUCAÇÃo: AÇões AFIRMA- TIVAS DE INCLUSÃO NO ENSINO SUPERIOR}

Ao longo da formação do meio acadêmico-universitário brasileiro, foi sendo construído um cenário fortemente marcado pela presença e pela constância de elementos de natureza étnica, de gênero e de natureza socioeconômica, de maneira a ser possível evidenciar a predominância de homens, brancos e "bem-nascidos" como protagonistas desses espaços, em que pesem as mudanças mais recentes nesse perfil, mas que ainda não foram capazes de alterar esses cenários, sobretudo em relação aos cursos de graduação mais prestigiados (PAIXÃO, 2010, p. 7). 
Objetivamente, constata-se um contraste entre esse cenário e o espírito democrático e universal que compõe a ideia de ensino e seu acesso estampados na Constituição Federal de 1988, sobretudo a redação do artigo 205, ao estabelecer que "a educação, direito de todos e dever do Estado e da família, será promovida e incentivada com a colaboração da sociedade, visando ao pleno desenvolvimento da pessoa, seu preparo para o exercício da cidadania e sua qualificação para o trabalho" (BRASIL, 1988).

O acesso à educação, mais especificamente o acesso ao ensino superior, poderia ser tratado satisfatoriamente ou exaustivamente pelas disposições iniciais do retrocitado dispositivo constitucional ao elevar o ensino à categoria de direito de todos e dever do Estado, assim, bastaria dizer que se trata de um direito de todos e que o Estado deveria assumi-lo. No entanto, essa constatação, por si só, não seria o suficiente para materializar as enormes distâncias existentes entre as disposições constitucionais e a realidade daqueles que poderiam ingressar no ensino superior. Trata-se de um problema maior, conjuntural, patriarcal, cultural e socioeconômico. É por essa razão que o acesso ao ensino superior precisa ser compreendido, de fato, como um direito de todos e um dever do Estado, mas, para além disso, também precisa ser compreendido a partir das amarras e dos limites que impedem ou limitam a efetividade desse dispositivo constitucional.

A partir disso, nos últimos anos, políticas públicas de ações afirmativas que propõem uma mudança na forma de acesso ao ensino superior brasileiro têm procurado aumentar a efetividade desse acesso como um direito de todos, ao tentar democratizá-lo por meio da ampliação da oferta e das condições de acesso. Assim, "ao fim da primeira década do século XXI, no Brasil, as ações afirmativas na educação superior podem ser consideradas, em seu conjunto, uma política pública que, efetivamente, tem colaborado para a inclusão de grupos subrepresentados, especialmente os de negros" (SILVA, 2016).

Um desses exemplos é a sanção presidencial da Lei $n^{0}$. 12.711, de 29 de agosto de 2012, que, ao dispor a respeito do ingresso de estudantes em instituições federais de ensino superior e técnico, estabeleceu 
como fator inclusivo o preenchimento de 50\% das vagas disponíveis, por curso e por turno, de seus cursos a estudantes que tenham realizado todo o ensino médio em escolas públicas e, no caso do ensino técnico, que tenham feito todo o ensino fundamental na rede pública de ensino. Além disso, o preenchimento da metade dessas vagas reservadas deverá ser destinado àqueles estudantes cujas famílias possuam renda per capita igual ou inferior a um salário mínimo e meio. Por fim, a ocupação dessas vagas reservadas deverá ser realizada por aqueles estudantes que se autodeclararem pretos, pardos e indígenas, em proporção, no mínimo, igual à população do mesmo grupo étnico da unidade da Federação na qual a instituição estiver instalada, tendo como parâmetros para aferição do quantitativo os dados obtidos por meio do último censo do Instituto Brasileiro de Geografia e Estatística (IBGE) (BRASIL, 2012).

Apesar de inquestionáveis os avanços gerados na ampliação do acesso ao Ensino Superior, por segmentos importantes da sociedade que historicamente não têm sido compreendidos como destinatários do Sistema Federal de Ensino Superior, ressalta-se que a Lei não atingiu expressamente as Instituições Estaduais de Ensino Superior, de forma que, Estados da Federação com tradição nesse segmento de ensino como o Estado do Paraná e o Estado de São Paulo, por exemplo, apresentam cenários bastante diversificados em relação à ocupação das vagas em seus cursos de graduação.

Exemplificativamente, no caso do Estado do Paraná, de acordo com o mapa do Ensino Superior, divulgado pela Secretaria de Estado da Ciência e Tecnologia, suas sete Universidades Estaduais possuem 99.942 estudantes e anualmente oferecem vagas em 267 cursos de graduação (PARANÁ, 2016). As vagas nesses cursos de graduação são preenchidas de maneira bastante diversa entre as instituições que compõem esse sistema.

Quando analisadas as duas maiores Universidades dessa Rede Estadual de Ensino Superior, a saber, a Universidade Estadual de Maringá e a Universidade Estadual de Londrina, por exemplo, evidencia-se que a Universidade Estadual de Maringá, em 2010, adotou o sistema de cotas sociais que destina $20 \%$ das vagas disponíveis em seus cursos de 
graduação a estudantes que tenham cursado todas as séries dos ensinos fundamental e médio na rede pública de ensino, que não possuam diploma de curso superior, que a renda per capita mensal de suas famílias não exceda a um salário mínimo e meio, que caso a família tenha bens patrimoniais, eles devem ser compatíveis com a renda declarada e não serem superiores a 30\% do limite estabelecido pela Receita Federal para entrega da Declaração de Imposto de Renda de Pessoa Física e, por fim, que as despesas básicas da família também sejam compatíveis com a renda informada (Resolução 12/2010-CEP).

No caso da Universidade Estadual de Londrina, a política de inclusão de estudantes em cursos de graduação remonta à publicação da Resolução nº 78 do Conselho Universitário, de 23 de julho de 2004.

Em linhas gerais, essa resolução determina que até $40 \%$ das vagas ofertadas nos cursos de graduação da Universidade Estadual de Londrina devem ser preenchidas por estudantes originários de instituições públicas de ensino. Além disso, também determina que até $20 \%$ desse quantitativo reservado deve ser preenchido por estudantes que se autodeclaram negros.

Em apertada síntese, constata-se que o alcance e a efetividade da Lei 12.711, de 29 de agosto de 2012 poderiam ter sido ampliados, caso as instituições estaduais de ensino também constassem no rol dos destinatários da implantação dessa política de inclusão, o que pode ser constatado pela divergência nas medidas de inclusão adotadas pelas Universidades Estaduais de Londrina e Maringá.

Recentemente, a Lei 12.711, de 29 de agosto de 2012, foi alterada pela Lei $n^{\circ}$. 13.409, de 28 de dezembro de 2016, para constar em seus artigos a distribuição das vagas em instituições federais de ensino, outrora destinadas somente aos estudantes da rede pública de ensino e àqueles integrantes de famílias com renda igual ou inferior a um salário mínimo e meio per capita, também aos deficientes. Dessa forma, distribui-se a reserva de vagas nas referidas instituições federais também aos estudantes deficientes, mas, novamente, as demais instituições de ensino superior, as estaduais, por exemplo, não foram eleitas como destinatárias para a adoção dessas medidas de inclusão. 
Em que pese o respeito à autonomia universitária, a implementação de uma política pública de inclusão, como é o caso da reserva de vagas para o ingresso nos cursos de graduação em instituições federais de ensino superior, deve ter seu alcance ampliado, em homenagem aos objetivos fundamentais do país, delineados na Constituição Federal de 1988, a saber: a redução das desigualdades sociais e regionais e a promoção do bem de todos, sem preconceitos ou discriminações de qualquer natureza.

Outra medida adotada no sentido de alterar o cenário de ocupação de vagas nas instituições de ensino superior é a sanção da Lei nº 11.096, de 13 de janeiro de 2005, que institui o Programa Universidade para todos - PROUNI.

Sob a responsabilidade do Ministério da Educação, o Programa destina-se à concessão de bolsas de estudos nas modalidades integrais e parciais em proporção de $25 \%$ e $50 \%$, para estudantes em cursos de graduação e sequenciais. Para ser beneficiário, a Lei determina que o estudante tenha cursado todo o ensino médio em instituição pública de ensino ou em instituições privadas na condição de bolsista integral. Também poderá ser bolsista o estudante portador de deficiência e o professor da rede pública de ensino, nos casos dos cursos de licenciatura, normal superior e pedagogia, destinados à formação do magistério da educação básica.

Finalmente, entre os critérios para a concessão, destaca-se a necessidade de os estudantes não possuírem diploma de curso superior e terem renda familiar mensal per capita não superior a um salário mínimo e meio, para os casos de bolsa integral e renda familiar mensal per capita não superior a três salários mínimos, para os casos de bolsas parciais de estudo nas proporções de $25 \%$ e $50 \%$, respeitados os critérios estabelecidos pelo Ministério da Educação.

Esse panorama de implementação de medidas que democratizam o acesso ao ensino superior aponta para a configuração de novos cenários no sistema de educação brasileiro, sobretudo o sistema público de ensino superior.

De acordo com dados do Instituto Brasileiro de Geografia e Estatística, divulgados por meio do relatório Síntese de Indicadores Sociais (SIS) 2014, observa-se que ao longo dos últimos anos, mais especificamente na última década, o perfil dos ingressantes no ensino superior, de 
18 a 24 anos de idade, tem sido substancialmente alterado, em que pese a persistência de algumas desigualdades históricas. O relatório destaca, por exemplo, que entre os anos de 2004 e 2013, houve uma redução na participação de estudantes mais ricos nesse sistema de ensino, de maneira que, em 2004, esse grupo de estudantes representava $55 \%$ dos estudantes da rede pública de ensino e $68,9 \%$ dos estudantes da rede privada. Quando analisados os dados de 2013, o relatório destaca que esses percentuais diminuem para $38,8 \%$ dos estudantes da rede pública e $43 \%$ da rede privada de ensino.

Essa primeira análise sinaliza para o aumento da participação de estudantes não pertencentes aos estratos mais altos da sociedade na rede de ensino superior, nas esferas públicas e privadas.

O relatório Síntese de Indicadores Sociais (SIS) 2015 destaca outro dado relevante em relação à ocupação de vagas no ensino superior. Trata-se da participação de estudantes, entre 18 e 24 anos de idade, pretos e pardos, no período compreendido entre 2004 e 2014, com exceção do ano de 2010, no qual a pesquisa não foi realizada.

Estudantes, de 18 a 24 anos de idade, pretos e pardos, matriculados no ensino superior, no período de 2004/2014.

\begin{tabular}{|c|c|}
\hline Ano & $\mathbf{1 0 0 \%}$ \\
\hline 2004 & 16,7 \\
\hline 2005 & 18,9 \\
\hline 2006 & 21,9 \\
\hline 2007 & 25,3 \\
\hline 2008 & 28,6 \\
\hline 2009 & 31,3 \\
\hline 2010 & - \\
\hline 2011 & 35,8 \\
\hline 2012 & 37,4 \\
\hline 2013 & 40,7 \\
\hline 2014 & 45,5 \\
\hline
\end{tabular}

Fonte: Instituto Brasileiro de Geografia e Estatística (2015) 
Apesar do aumento na porcentagem de negros e pardos, de 18 a 24 anos de idade, no ensino superior, Corbucci (2014, p. 21) destaca que ainda persiste um hiato entre a proporção de jovens brancos e a proporção de jovens pretos e pardos matriculados no ensino superior. Para ele, a partir da análise de microdados do censo demográfico do IBGE, é possível constatar que:

...jovens pardos e pretos têm desvantagem de $60 \%$ a $65 \%$ em relação a brancos, no que concerne ao acesso à educação superior, considerando-se para tanto os que frequentavam e aqueles que tiveram acesso a este nível de ensino.

O que se verifica é que as ações afirmativas, independente da sua modalidade, sejam elas de matriz socioeconômica ou étnico-racial, constituem medida importante de democratização do acesso ao ensino e, dessa forma, conferem maior efetividade ao direito à educação. Em que pese esse reconhecimento, há necessidade de ampliação do acesso e de integração de outros agentes no ensino superior brasileiro na implementação dessa política pública de democratização do ensino, de forma a caracterizá-lo, minimamente, como um sistema de ensino mais universal e democrático, no sentido de que quaisquer interessados tenham condições de participação em seus processos seletivos, sejam eles conduzidos em âmbito federal ou estadual, que possam integrar e permanecer nesses sistemas de ensino superior.

\section{CONSIDERAÇões FINAIS}

$\mathrm{O}$ direito à educação representa o direito a uma perspectiva de melhoria na qualidade de vida dos cidadãos, à medida que amplia suas possibilidades de oportunidades e pode contribuir para a promoção de uma sociedade menos desigual, mais consciente e crítica da realidade. A educação é um instrumento estratégico, essencialmente político, que tanto pode favorecer a expressão da justiça e a efetividade de direitos, como também, perpetuar condições de exclusão social. 
As ações afirmativas, como medidas urgentes e temporárias, possibilitam mudanças profundas na realidade social e influenciam o percurso histórico, estimulando o empoderamento dos cidadãos historicamente negligenciados pelo poder público, marcados pela violência física e moral, de forma explícita, sutil ou subjetiva. A reiterada negação da existência de preconceito no Brasil, a prática de subordinação de determinados grupos étnico-raciais, em diversos setores da sociedade, a distorção das características identitárias desses grupos, e a própria dinâmica de exclusão de direitos, são desafios contínuos, que justificam a busca por transformações concretas.

Além disso, é preciso salientar que os avanços, em direção às políticas públicas voltadas às ações afirmativas, só puderam ser efetivados por meio de lutas reivindicatórias dos movimentos sociais, das classes populares e dos povos afrodescendentes e indígenas, e foram legitimados pelo estabelecimento de leis, porém, sua articulação com a prática social e, por conseguinte, com a prática educacional, ainda requer um processo contínuo de diálogo.

\section{REFERÊNCIAS}

Barbosa, Fernando Cesar Mendes; Merheb, Marcos Paulo dos Santos BAHIG. ENSAIO ACERCA DOS DiReITOS FUNDAMENTAIS: A RELAÇÃo ENTRE CONSTITUCIOnalismo e direitos fundamentais. In: SANTOS, Carlos Victor Nascimento et al. (Orgs.). Direitos e Garantias Fundamentais III: Desigualdade e Desenvolvimento: papel do Direito nas políticas públicas. Brasília: CONPEDI, 2017, Р. 244-260.

BONAVIDES. Paulo. Curso de direito constitucional. São Paulo: Malheiros, 2002.

BRASIL. Constituição (1988). Constituição da República Federativa do Brasil de 1988. Diário Oficial da União, Brasília, DF, n. 191, 5 de out. de 1988. Seção I, p. 1.

. Lei $\mathrm{n}^{\circ} .5 .692$, de 11 de agosto de 1971. Fixa Diretrizes e Bases para o ensino de $1^{\circ}$. e $2^{\circ}$ graus, e dá outras providências. Diário Oficial da União. Brasília, DF, n. 253, 12 de ago. de 1971. Seção I, p. 6.377. 
. Lei $n^{\circ} .9 .394$, de 20 de dezembro de 1996. Estabelece as diretrizes e bases da educação nacional. Diário Oficial da União. Brasília, DF, n. 248, 23 dez. 1996. Seção I, p. 27.833.

. Lei $\mathrm{n}^{\circ} .10 .639$, de 9 de janeiro de 2003. Brasília, DF, 10 de janeiro de 2003. Altera a Lei $n^{\circ}$. 9.394, de 20 de dezembro de 1996, que estabelece as diretrizes e bases da educação nacional, para incluir no currículo oficial da Rede de Ensino a obrigatoriedade da temática "História e Cultura Afro-Brasileira", e dá outras providências. Diário Oficial da União, Brasília, DF, n. 8, 10 jan. 2003. Seção I, p. 1.

. Lei no ${ }^{\circ}$ 11.096, de 13 de janeiro de 2005. Institui o Programa Universidade para Todos - PROUNI, regula a atuação de entidades beneficentes de assistência social no ensino superior; altera a Lei $\mathrm{n}^{\circ}$. 10.891, de 9 de julho de 2004, e dá outras providências. Diário Oficial da União, Brasília, DF, n. 10, 14 jan. 2005. Seção I, p. 7.

. Lei $\mathrm{n}^{\circ} .11 .645$, de 10 de março de 2008. Altera a Lei $\mathrm{n}^{\circ} .9 .394$, de 20 de dezembro de 1996, modificada pela Lei $\mathrm{n}^{\circ}$. 10.639, de 9 de janeiro de 2003, que estabelece as diretrizes e bases da educação nacional, para incluir no currículo oficial da rede de ensino a obrigatoriedade da temática "História e Cultura Afro-Brasileira e Indígena”. Diário Oficial da União. Brasília, DF, n. 48, 11 mar. 2008. Seção I, p. 1.

. Lei $\mathrm{n}^{\circ} .12 .711$, de 29 de agosto de 2012. Dispõe sobre o ingresso nas universidades federais e nas instituições federais de ensino técnico de nível médio e dá outras providências. Diário Oficial da União. Brasília, DF, n. 169, 30 de ago. de 2012. Seção I, p. 1.

. Lei $\mathrm{n}^{\mathrm{o}}$. 13.409, de 28 de dezembro de 2016. Altera a Lei $\mathrm{n}^{\mathrm{o}}$. 12.711, de 29 de agosto de 2012, para dispor sobre a reserva de vagas para pessoas com deficiência nos cursos técnico de nível médio e superior das instituições federais de ensino. Diário Oficial da União. Brasília, DF, n. 250, 29 dez. 2016. Seção I, p. 3.

CORBUCCI, Paulo Roberto. Evolução do acesso de jovens à Educação Superior no Brasil. Instituto de Pesquisa Econômica Aplicada. Rio de Janeiro: Ipea, 1990. Disponível em: <http://www.ipea.gov.br/portal/images/stories/ PDFs/TDs/td_1950.pdf > . Acesso em: $1^{\circ}$. nov. 2016. 
FONSECA, Dagoberto José. Políticas Públicas e Ações Afirmativas. São Paulo: Selo Negro, 2009.

FREIRE, Paulo. Pedagogia do oprimido, 17. ed. Rio de Janeiro: Paz e Terra, 1987.

IBGE. Instituto Brasileiro de Geografia e Estatística. Síntese de Indicadores Sociais 2014: Uma análise das condições de vida da população brasileira. Rio de Janeiro: IBGE, 2014. Disponível em: < http://biblioteca.ibge.gov.br/visualizacao/livros/liv91983.pdf>. Acesso em: 1º dez. 2016.

Síntese de Indicadores Sociais 2015: Uma análise das condições de vida da população brasileira. Rio de Janeiro: IBGE, 2015. Disponível em: <http://biblioteca.ibge.gov.br/visualizacao/livros/liv95011.pdf>. Acesso em: $1^{\circ}$. dez. 2016.

PAIXÃO, Marcelo. Diversidade e multiculturalismo: novos rumos para a Universidade brasileira. In: MONTEIRO, Aloisio Jorge de Jesus; SISS, Ahyass (Orgs.). Negros, Indígenas e a educação superior. Rio de Janeiro: Quartet; EDUR, 2010, p. 7.

PARANÁ. Secretaria de Estado da Ciência e Tecnologia. Cursos Ofertados. Disponível em: <http://www.seti.pr.gov.br/arquivos/File/MAPA_Cursos.pdf>. Acesso em: 4 nov. 2016.

PARANÁ. Universidade Estadual de Londrina. Resolução 74/2004-CU, de 23 de julho de 2004. Londrina, PR, 23 de jul. de 2004. Disponível em $<$ http:// www.uel.br/prograd/docs_prograd/resolucoes/resolucao_78_04.pdf $>$. Acesso em: 10 nov. 2016.

PARANÁ. Universidade Estadual de Maringá. Resolução 12/2010-CEP, de $1^{\circ}$. de dezembro de 2010. Maringá, PR, $1^{\circ}$. de dez. de 2010. Disponível em: $<$ http://www.npd.uem.br/cvu/relatorios/0/Resoluao012_2010CEP.pdf $>$. Acesso em: 10 nov. 2016.

SANTOS, João Paulo de Faria. Ações afirmativas e igualdade racial: a contribuição do direito na construção de um Brasil diverso. São Paulo: Edições Loyola, 2005.

SARLET. Ingo Wolfang. A eficácia dos direitos fundamentais, 4. ed. Porto Alegre: Livraria dos Advogados, 2004. 
SILVA, José Afonso da. Curso de Direito Constitucional Positivo, 35. ed. São Paulo: Malheiros, 2012.

SILVA, Marcos Antônio Batista da. Políticas e práticas contemporâneas sobre relações raciais e a pós-graduação. Revista Brasileira de Pós-Graduação, Brasília, v. 13, n. 30, p. 105-127, jan./abr. 2016.

\section{SOBRE OS AUTORES}

Fernando Cesar Mendes Barbosa

Discente do Programa de Pós-Graduação Stricto Sensu em Ciência Jurídica da Universidade Estadual do Norte do Paraná. Advogado. Licenciado em Letras e em Filosofia. Especialista em Educação pela Universidade Tecnológica Federal do Paraná. Servidor da Universidade Federal da Integração Latino-Americana - UNILA.

E-mail: fernandocesarmb@gmail.com

Fabiano Simon Brunetto

Advogado. Graduado em Direito pela UNIFOZ - Faculdades Unificadas de Foz do Iguaçu. Servidor da Universidade Federal da Integração Latino-Americana - UNILA. Foz do Iguaçu/PR - Brasil.

E-mail: fabiano.brunetto@gmail.com

Rosilene Alves da Silva Vitorini

Especialista em Educação Especial e Inclusiva. Graduada em Pedagogia pela UENP - Universidade Estadual do Norte do Paraná. Pedagoga na Universidade Federal da Integração Latino-Americana. Foz do Iguaçu/PR - Brasil.

E-mail: vitorinirosi@gmail.com

Submetido em: 10-7-2017

Aceito em: 2-10-2017 